\title{
Morbidity of schistosomiasis mansoni in the state of Minas Gerais, Brazil
}

\author{
Sandra Costa Drummond, Luciana Cristina dos Santos Silva*, \\ Ronaldo Santos do Amaral**, Silvio Roberto Sousa-Pereira*, Carlos Maurício Antunes*, \\ José Roberto Lambertucci*/+
}

Secretaria de Saúde do Estado de Minas Gerais, Belo Horizonte, MG, Brasil *Faculdade de Medicina da Universidade Federal de Minas Gerais, Serviço de Doenças Infecciosas e Parasitárias, Av. Antonio Carlos 6627, 31270-910 Belo Horizonte, MG, Brasil

**Secretaria de Vigilância em Saúde, Ministério da Saúde, Brasil

From 2002 to 2005, a program of active search for patients with hepatosplenic schistosomiasis and schistosomal myeloradiculopathy has been implemented in the state of Minas Gerais by the local Health Department. The state was divided in 28 regional health centers and the local representatives have been trained to identify and direct patients with hepatosplenic schistosomiasis and neuroschistosomiasis to a reference center in Belo Horizonte, the capital of the state of Minas Gerais. Seventy five patients with hepatosplenic schistosomiasis and 54 with schistosomal myeloradiculopathy have been referred and examined in the reference center in a period of time of 3 years. Schistosomal myeloradiculopathy should be emphasized because the number of cases reported is increasing rapidly and when timely diagnosed and treated, they respond promptly to treatment. Left untreated, they die or become invalid for life. In our view, the time has come for more active investigation of the different aspects of morbidity caused by schistosomiasis mansoni in Brazil.

Key words: schistosomiasis - hepatosplenic schistosomiasis - neuroschistosomiasis - magnetic resonance imaging myeloradiculopathy

It has been estimated that 4 to 6 million people are infected by Schistosoma mansoni in Brazil and that the states of Minas Gerais and Bahia concentrate $70 \%$ of the cases. Based on two national surveys of schistosomiasis performed in Brazil (Amaral \& Porto 1994, Coura \& Amaral 2004) we have learnt that many areas had a prevalence of S. mansoni infection over 15\% (Fig. 1, map of distribution of schistosomiasis in Brazil).

Up to 1999 the Brazilian Program of Schistosomiasis Control was centralized in Brasília (capital of Brazil) and was coordinated and administered by the National Health Foundation (Ministry of Health). In 2000, health programs were decentralized and the control of diseases was transferred to each state. Since then, the Minas Gerais Health Department has assumed full responsibility for the surveillance and control of schistosomiasis in the state with technical and logistic support of the Central Government, when demanded. At this point it was clear that evaluation of morbidity of schistosomiasis should be incorporated to the program.

Schistosomiasis is a disease of compulsory notification in Brazil, outside the endemic areas, but severe forms of the disease and its complications are not requested in the notification protocol standardized and provided by the government (called 'National System of Notification of Injuries' - Sinan in Portuguese).

${ }^{+}$Corresponding author: lamber@uai.com.br

Received 25 May 2006

Accepted 26 June 2006
It is important to mention that studies about morbidity of schistosomiasis have not been included in national surveys, and the information we have about morbidity in Brazil come from independent and isolated reports - some of good quality - collected by Brazilian scientists working in different endemic areas of the country (Lambertucci et al. 1987, 1996, Prata 2004).

Herein we report preliminary data on morbidity of schistosomiasis, in particular of hepatosplenic schistosomiasis and neuroschistosomiasis, obtained from 2002 to 2005 in a Reference Center for Infectious Diseases in the state of Minas Gerais, in Brazil.

\section{PATIENTS AND METHODS}

Endemic area - In Fig. 2 is depicted the endemic area for schistosomiasis in Minas Gerais as of December, 2005. It comprises 523 cities, being 518 contiguous and 5 scattered over the state (Fig. 3), with a population at risk of infection of 9 million people out of 16 million inhabitants. In 440 cities, the Schistosomiasis Control Program (PCE in Portuguese) has been implemented. It includes repeated stool examinations (every two years) and treatment of positive cases; in local schools, health education activities emphasize the importance of schistosomiasis, and a sanitation program has been implanted in some areas with the help of local communities interested in the control of the disease and willing to work as a team (e.g., construction of sanitary facilities).

Patients and study design - In 2002, in the city of Belo Horizonte (capital of the state of Minas Gerais) a group of Brazilian scientists, physicians and technical personnel from PAHO (Pan American Health Organization), National Health Foundation (Funasa), René Rachou-Research Cen- 


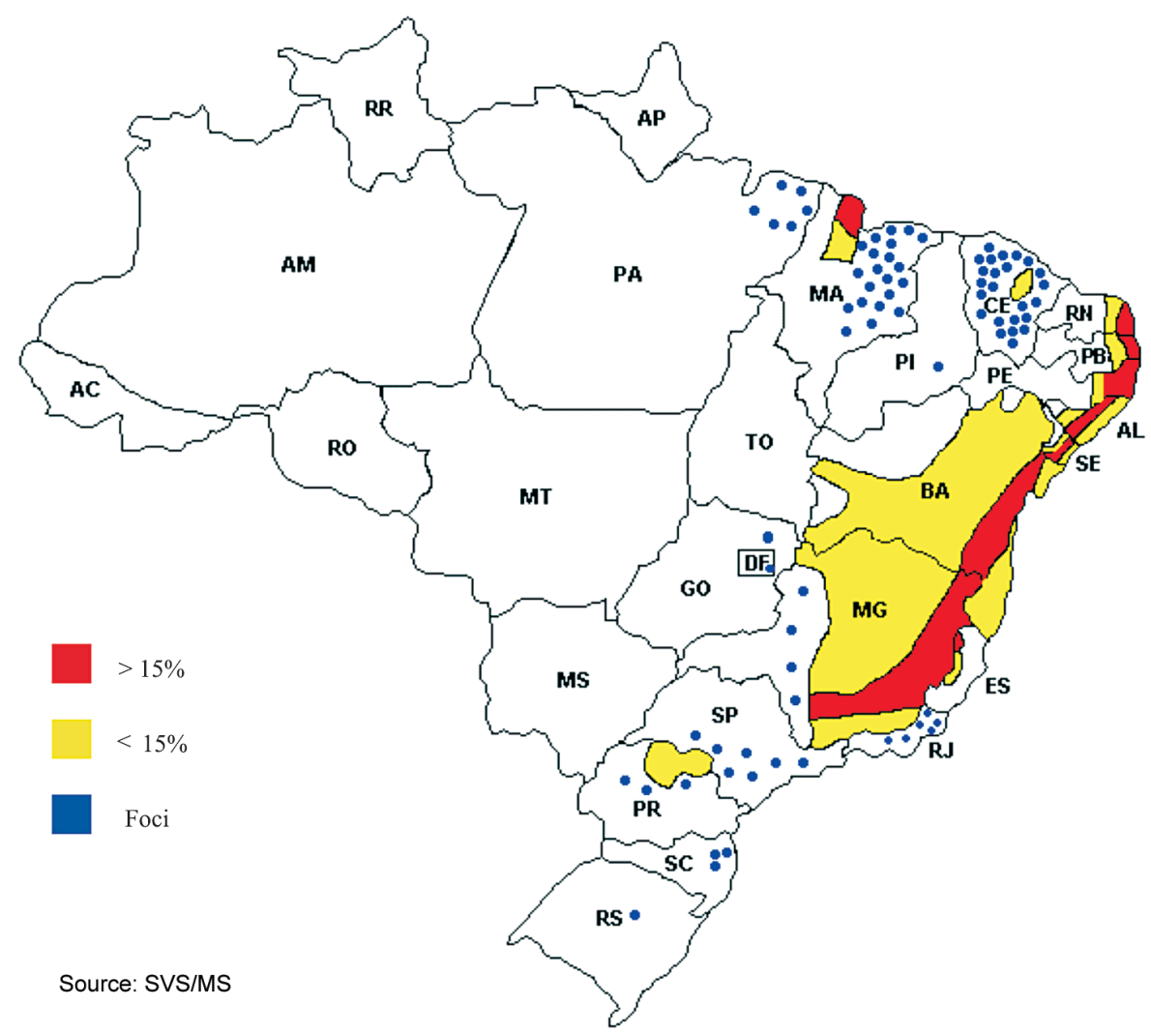

Fig. 1: distribution of schistosomiasis in Brazil.

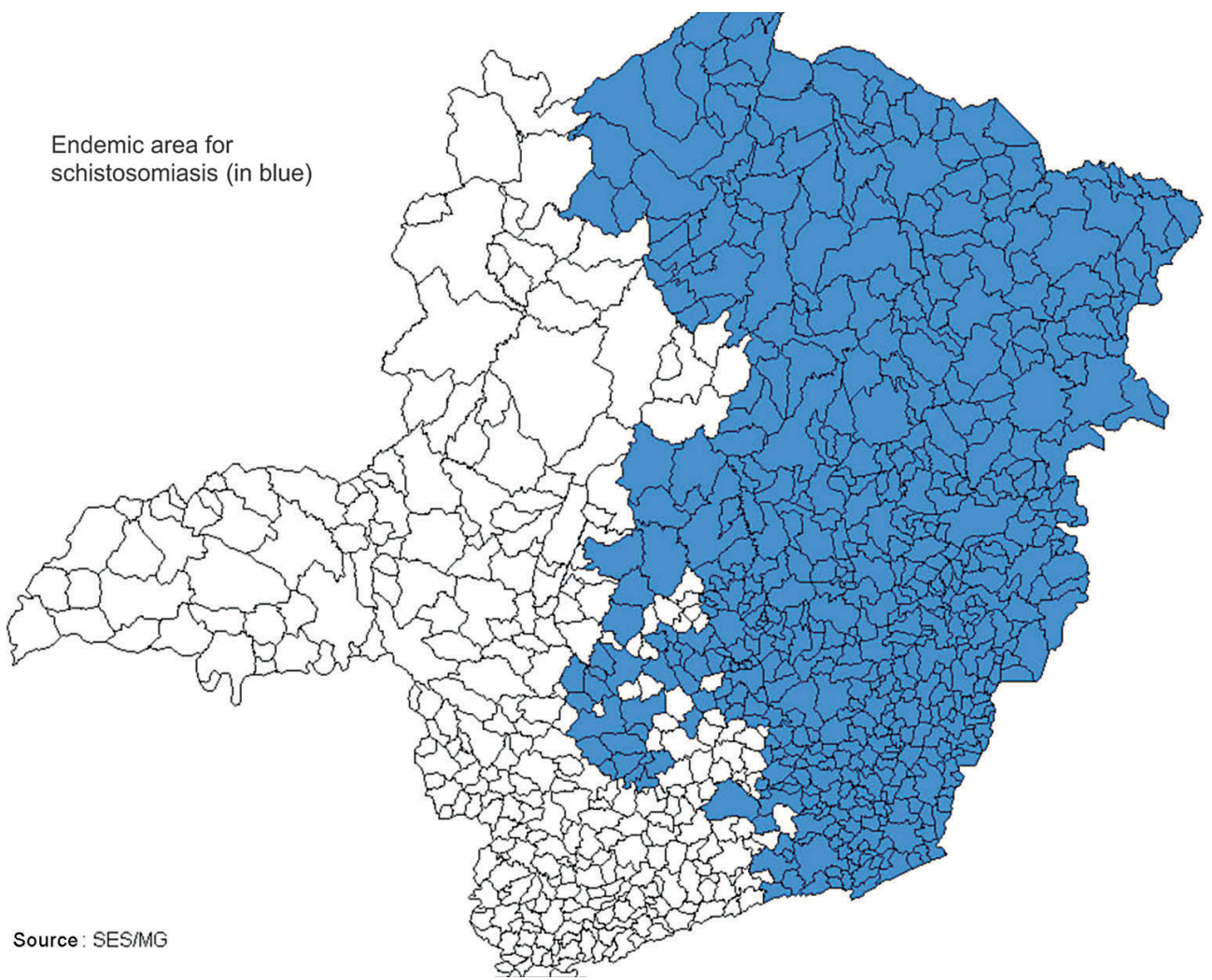

Fig. 2: endemic area for schistosomiasis in the state of Minas Gerais, Brazil. 


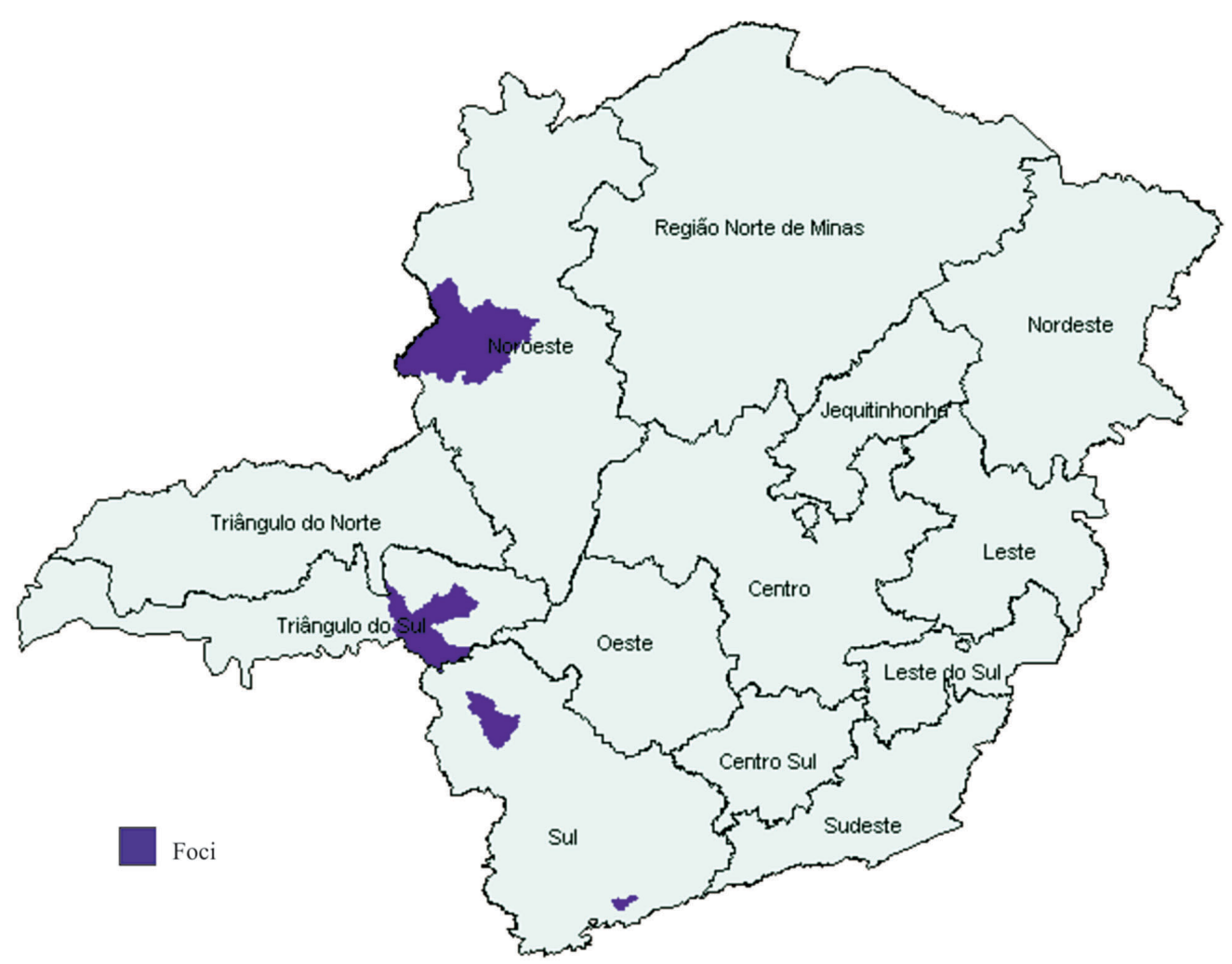

Fig. 3: areas of foci of schistosomiasis mansoni in the state of Minas Gerais, Brazil.

ter (Fiocruz-Brazil), Faculty of Medicine of the Federal University of Minas Gerais, the Minas Gerais Health Department, and its Regional Managers (Gerentes Regionais de Saúde - GRS) was convened to discuss different aspects of schistosomiasis in Brazil, with particular interest in the state of Minas Gerais. The topics presented by experts were: Schistosomiasis in Brazil and in Minas Gerais, The control Program, Intermediate Hosts, Diagnosis, Clinical Aspects and Treatment. On the course of the meeting, cases of schistosomal myeloradiculopathy were presented and it became clear that some aspects of schistosomal morbidity have been neglected over the years (Lambertucci et al. 2000, Silva et al. 2004a, b).

Directives were approved during the meeting to adapt the program to the state and among these was the suggestion for a careful investigation of morbidity with emphasis in two aspects: neuroschistosomiasis and the hepatosplenic form of the disease. Posters and folders were produced and distributed to 28 sections of the Health Department spread all over the state. Patients of every municipality with evidence of neuroschistosomiasis (back pain, urinary dysfunction, and lower limbs parestesia or weakness) or hepatosplenic schistosomiasis (hepatosplenomegaly, ultrasound showing periportal fibrosis, eggs of $S$. mansoni in the stools) should be referred to the Health Regional Managers and they were made responsible for finding the means to transfer the sick to an out patient clinic of the Faculty of Medicine, Federal University of Minas Gerais, in Belo Horizonte, where standardized tests would confirm or exclude the diagnosis, and adequate treatment would be provided. The study has been approved by the Ethical Committee of the Federal University of Minas Gerais, Brazil.

Study protocol for schistosomal myeloradiculopathy - Patients considered for the study were those presenting with lumbar and/or lower limb pain; lower limb weakness; anesthesia, hypoesthesia, or paresthesia; bladder and/or intestinal dysfunction; and sexual impotence. Stool examination was done on three samples obtained in different days by a sedimentation-concentration method. Rectal biopsy was done for patients whose stool examination did not reveal $S$. mansoni eggs following a routine procedure. ELISA was used to seek IgA and IgG antibodies to schistosomal soluble egg antigen. To exclude other causes of transverse myelitis, the following tests were performed or measurements made: complete history, clinical and neurological examination, blood cell count, prothrombin time, fasting glucose, serum cyanocobalamin, lupus anticoagulant, antinuclear antibodies, venereal disease research laboratory (VDRL) test, hepatitis B surface antigen, antibody to hepatitis B surface antigen, antibody to hepatitis $\mathrm{B}$ core antigen, IgM antibodies to cytomegalovirus and herpes simplex virus, antibodies to human T lymphotropic virus types 1 and 2, and antibody to HIV. All patients underwent abdominal ultrasound examinations to evaluate the presence of periportal fibrosis. Biochemistry and cytomorphological examinations of CSF specimens obtained by lumbar puncture were also done. Magnetic sonance imaging of the spinal cord was done to investi- 
gate the aspects of SMR before and after treatment and to exclude other causes of transverse myelitis. Magnetic resonance imaging studies were done on a Magnetom Impact Expert superconducting 1.0 Tesla magnetic system (Siemens). Magnetic resource imagings were obtained in sagittal and axial projections with repetition time (TR) of 500-700 $\mathrm{ms}$ and echo time (TE) of 12-15 ms for T1-weighted images. The longer TR/TE (T2-weighted) images were acquired with TRs of 2000-5000 ms and TEs of 60-112 ms. T1 sequences were also obtained after intravenous administration of gadopentetate dimeglumine contrast material (gadolinium, $0.1 \mathrm{mmol} / \mathrm{kg}$ of body weight). Slice thickness was $2-5 \mathrm{~mm}$. Patients were treated with oral praziquantel $(50 \mathrm{mg} / \mathrm{kg}$ in a single dose) and received methylprednisolone (15 mg/kg q.d. iv; maximum dose, 1 g q.d.) for five days, followed by prednisone $(1 \mathrm{mg} / \mathrm{kg}$ q.d. po) for six months (Braga et al. 2003, Silva et al. 2002, 2004b).

Study protocol for hepatosplenic schistosomiasis The diagnosis of hepatosplenic schistosomiasis was based on the presence of a palpable liver and spleen on clinical examination and also in the presence of characteristic liver fibrosis diagnosed by ultrasound (Pinto-Silva et al. 1994, Gerspacher-Lara et al. 1998, Lambertucci et al. 2001, Richter et al. 2001). Serological tests for hepatitis B and $\mathrm{C}$ were performed to exclude the association of diseases (Serufo et al. 1998).

Ultrasound - Abdominal ultrasound was performed by a radiologist who was unaware of the patient's clinical status using real time equipment (PHILLIPS ATL-HDI 1500 scanner with a 2 to $5 \mathrm{MHz}$ transducer). The degree of periportal fibrosis was graded as reported by our group: (1) slight echogenic thickening of the wall of less than 1/ 3 of peripheral portal branches or normal liver; (2) moderate to severe wall thickening ( $>2 \mathrm{~mm}$ ) of more than $1 / 3$ of peripheral portal branches. We measured the size of the right and left lobe of the liver, the spleen length in craniocaudal extension, the diameter and the wall thickness of the gallbladder; portal veins system, including the first, second, and third portal vein branches (Gerspacher-Lara et al. 1997, Richter et al. 2001). Splenomegaly was established when the spleen length in cranio-caudal extension exceeded the height-adjusted normal value published by WHO in 2001.

Statistical analysis - This is a descriptive study and data were presented in tables, maps, and figures.

\section{RESULTS}

From September, 2002 to September, 2005, 129 patients with severe schistosomiasis mansoni were referred to our out patient clinic and were submitted to clinical, laboratory, ultrasound, and magnetic resonance imaging examinations. Seventy five (58.1\%) had hepatosplenic schistosomiasis in the age range of 20 to 75 years (mean $=43.5$; median $=45 ; 61$ were male), and $54(41.9 \%)$, schistosomal myeloradiculopathy in the age range of 13 to 60 years ( mean $=36$; median $=30 ; 74$ were male). In Tables I and II are shown the cities of origin of the patients and in Figs 4 and 5 the data have been plotted in a map of the state.

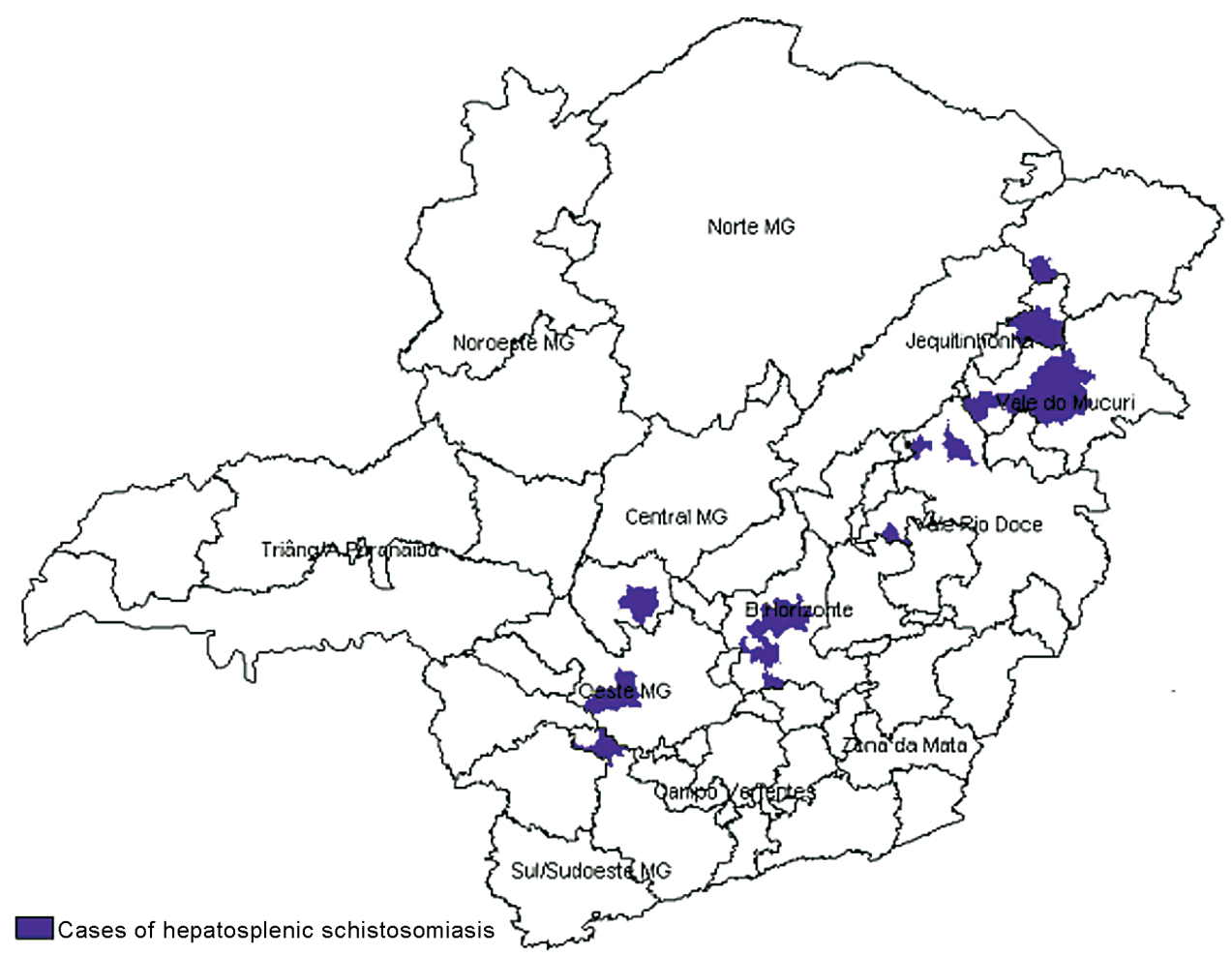

Fig. 4: distribution of cases of hepatosplenic schistosomiasis mansoni by city of origin, registered at the out patient clinic of the Infectious Diseases Branch of the Faculty of Medicine, Federal University of Minas Gerais, in Brazil, from 2002 to 2005. 


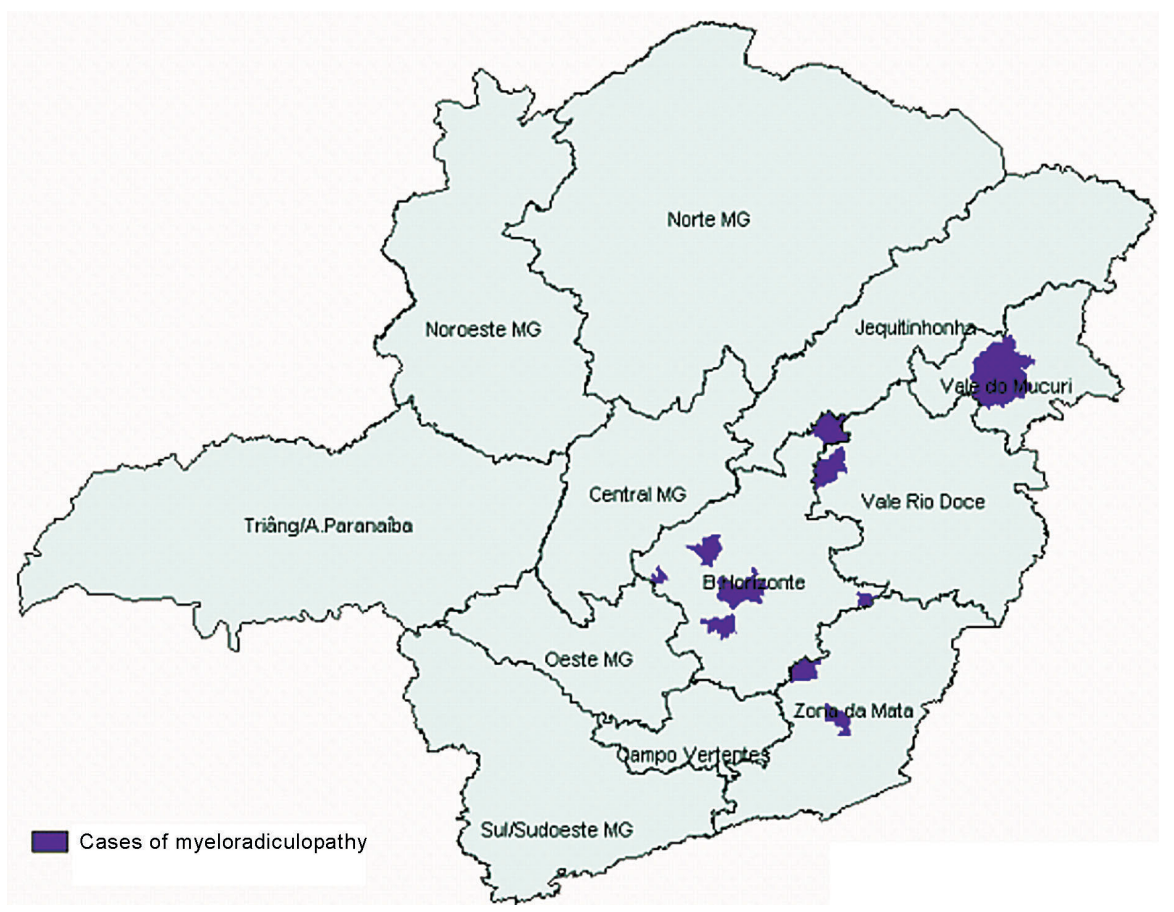

Fig. 5: distribution of cases of schistosomal myeloradiculopathy by city of origin registered at the out patient clinic of the Infectious Diseases Branch of the Faculty of Medicine, Federal University of Minas Gerais, Brazil, from 2002 to 2005.

\section{TABLE I}

Distribution of cases of schistosomal myeloradiculopathy by city of origin registered at the out patient clinic of the infectious diseases branch of the Faculty of Medicine, Federal University of Minas Gerais, Brazil, from 2002-2005

\section{Cities} Number of cases

Belo Horizonte

Betim

Brumadinho

Carlos Chagas

Central de Minas

Coimbra

Contagem

Itabira

Juiz de Fora

Mariana

Mário Campos

Onça do Pitangui

Pescador

Piranga

Porto Firme

Ribeirão das Neves

Rio Vermelho

Sabará

Sabinópolis

Santa Luzia

São José do Goiabal

Sete Lagoas

Ubá

Vespasiano

Viçosa

\begin{tabular}{lr}
\hline Not registered & 2 \\
\hline Total & 54
\end{tabular}

\section{TABLE II}

Distribution of cases of hepatosplenic schistosomiasis mansoni by city of origin, registered at the out patient clinic of the infectious diseases branch of the Faculty of Medicine, Federal University of Minas Gerais, Brazil, from 2002 to 2005

Cinis

Água Boa

Belo Horizonte

Belo Vale

Betim

Boa Esperança

Bom Despacho

Brumadinho

Caeté

Caraí

Contagem

Comercinho

Formiga

Igarapé

Itabira

Padre Paraíso

Pedro Leopoldo

Poté

Ribeirão das Neves Number of cases

Sabará

Santa Luzia

Santa Maria do Suaçuí

Sarzedo

São José da Lapa

Teófilo Otoni

Turmalina

Vespasiano

\begin{tabular}{lr}
\hline Not registered & 2 \\
\hline Total & 75
\end{tabular}



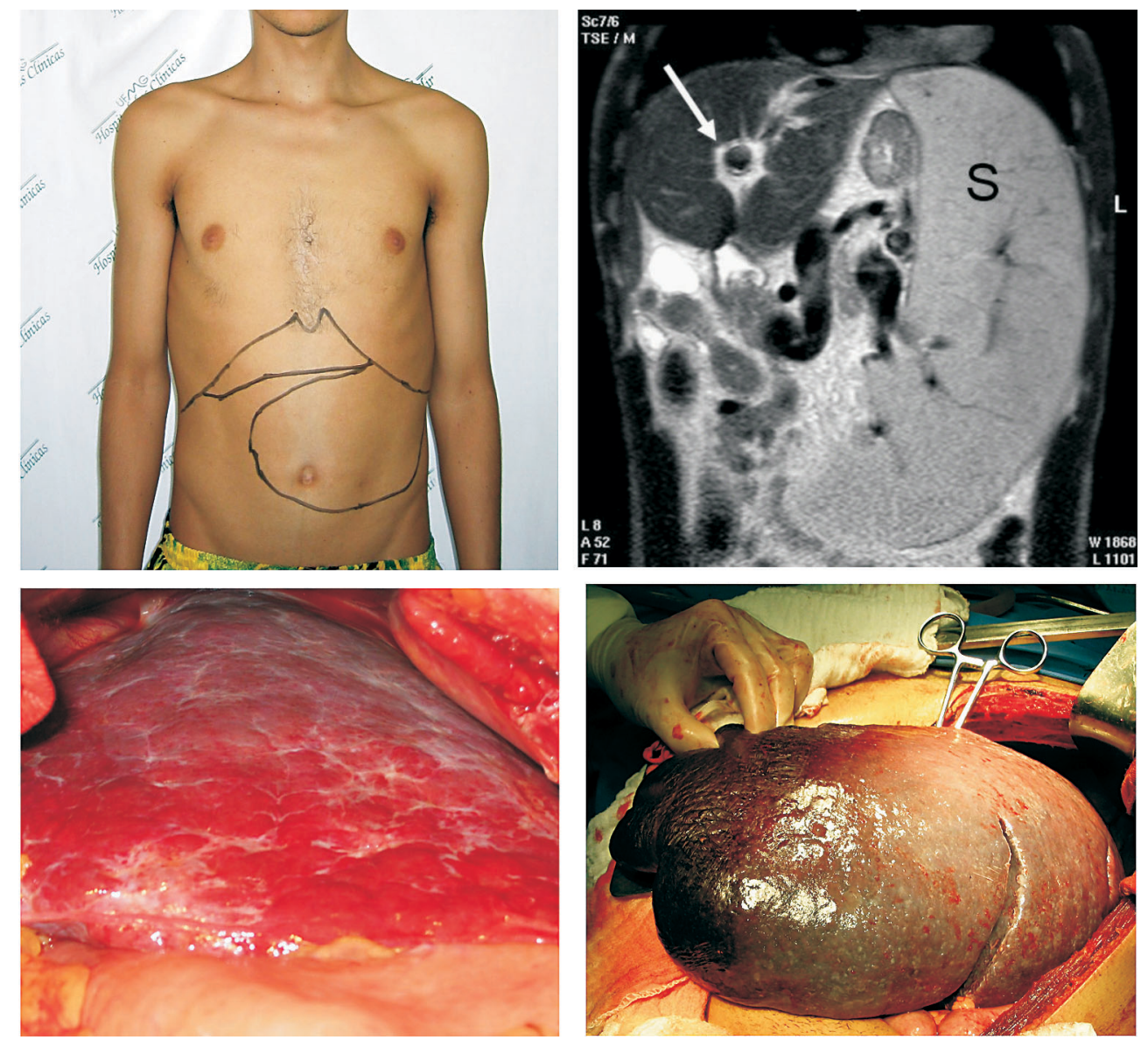

Fig. 6: a 21-year-old patient with hepatosplenic schistosomiasis. On the upper right hand side, a coronal section of the abdomen captured by magnetic resonance imaging (MRI), showing periportal fibrosis (white arrow) and a huge spleen (S). It is shown below, during surgery, the nodular surface of the liver (on the left) and the spleen (on the right).

In Fig. 6 is shown the case of a patient with severe hepatosplenic schistosomiasis who was admitted to hospital with a huge spleen, hypersplenism, variceal bleeding, and periportal fibrosis on ultrasound. He was operated on for portal hypertension and chronic anemia which did not respond to iron replacement (splenectomy + esophagogastric devascularization).

In Fig. 7 is shown the case of a young patient with schistosomal myeloradiculopathy being admitted to hospital in a wheel chair with paraplegia and urinary retention. Magnetic resonance imaging showed alterations in the spinal cord which suggested the diagnosis of schistosomal myeloradiculopathy. All tests performed to exclude other diseases resulted negative. Complete recovery was obtained after treatment with steroids and praziquantel.

\section{DISCUSSION}

Seventy five patients with hepatosplenic schistosomiasis and 54 with schistosomal myeloradiculopathy have been examined in an out patient clinic of a reference center for schistosomiasis mansoni in Belo Horizonte, Brazil in a period of time of three years. This large number of patients with severe manifestations of the disease came from different parts of the state and they were actively searched for by local health professional, specifically trained for this purpose by the Health Department of the state of Minas Gerais. The median age for the hepatosplenics was 45 years and for those with myeloradiculopathy it was 30 years with a predominance of males in both groups.

Our previous filling that morbidity of schistosomiasis mansoni in Brazil and in other endemic areas has been underestimated seems to be confirmed, for Brazil, by our findings. In our view, the time has come for a more active approach to diagnosis and treatment of patients with severe schistosomiasis mansoni. In fact, we have been dealing here with neglected aspects of morbidity of a neglected disease (Petroianu 2003, Lambertucci et al. 2004, 2005).

The case of patients with schistosomal myeloradiculopathy should be emphasized. In the last 10 years, the number of cases reported has escalated rapidly in the literature and physicians are becoming aware of a complication of schistosomiasis that was not considered to be an 

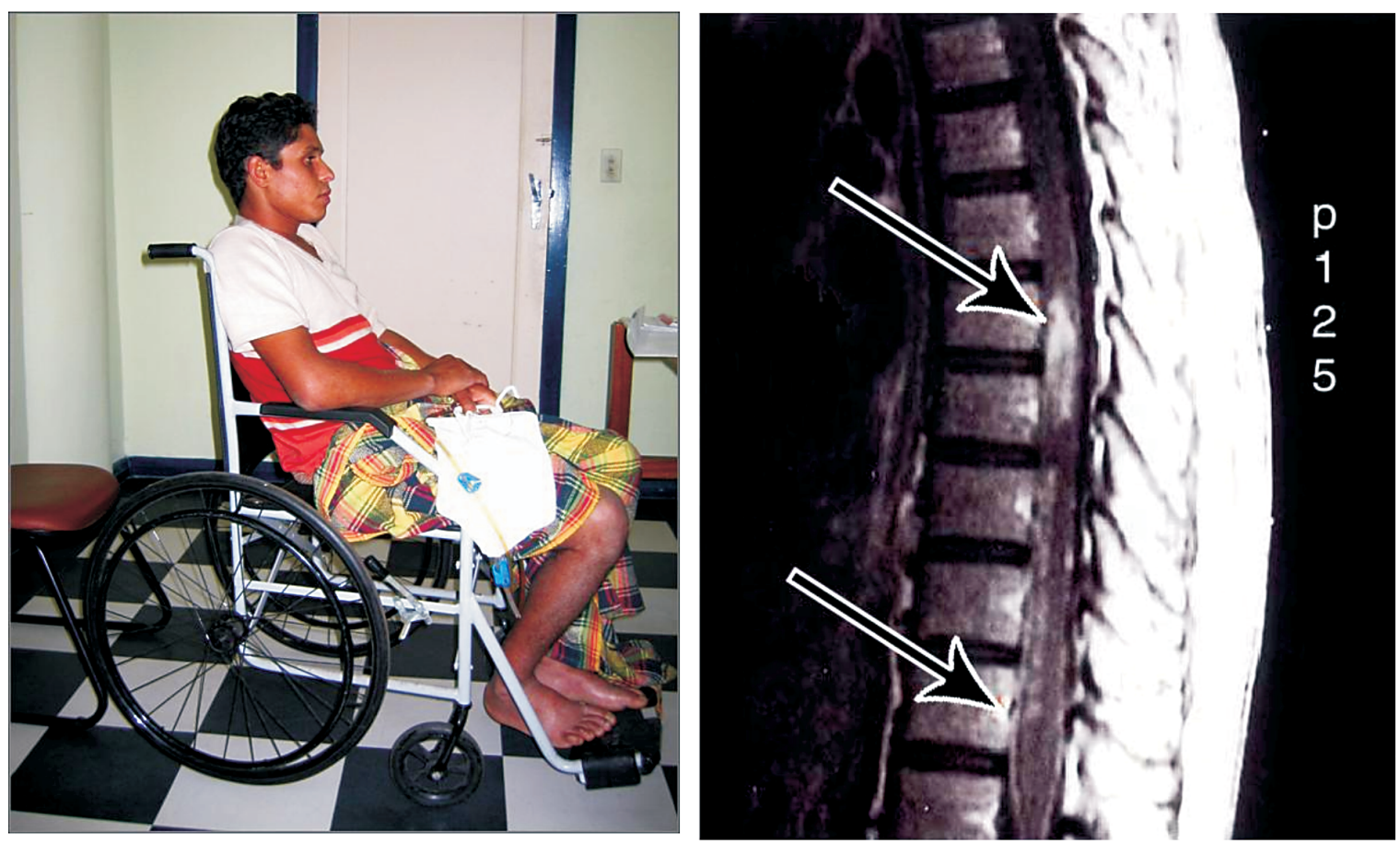

Fig. 7: this is a 24-year-old patient being admitted to hospital with paraplegia, urinary and fecal retention caused by schistosomiasis mansoni. On the right hand side, magnetic resonance imaging after gadolinium injection shows hyperintense signal along the spinal cord with dilation of the conus medullaris (lower arrow).

important problem until very recently. The use of magnetic resonance imaging for diagnosis of diseases of the spinal cord has, in fact, increased our perception of the importance of schistosomiasis as a cause of myelitis in Brazil. Patients with involvement of the spinal cord which are not diagnosed and treated accordingly usually die or become invalid for life (paraplegia, urinary and fecal retention, impotence). When timely diagnosed and treated, recovery is complete in most cases (Lambertucci et al. 2005).

The median age for patients with hepatosplenic schistosomiasis was 45 years. This seems to corroborate previous reports that morbidity, in the case of hepatosplenics, is decreasing in the young population due to the program of mass chemotherapy of schistosomiasis implemented in Brazil since the seventies of the last century.

It is worth mentioning that most patients with hepatosplenic schistosomiasis (41.3\%) and schistosomal myeloradiculopathy (38.9\%), in our study, came from Belo Horizonte and also from other small cities around Belo Horizonte. In part, this may be explained by the migration of infected people to the outskirts of large cities and/or because it is easier for the sick to have access to medical services of good quality in reference centers.

In short, our findings reinforce the need to bring back schistosomiasis into the agenda of the government of Brazil as a serious health problem that should be faced promptly to avoid severe avoidable complications of the disease as reported herein. It is also time to consider other aspects of morbidity as pulmonary hypertension, glomerulonephritis, and the association with other diseases.

\section{REFERENCES}

Amaral RS, Porto MAS 1994. Evolução e situação atual do controle da esquistossomose no Brasil. Rev Soc Bras Med Trop 27 (Supl. 3): 73-90.

Braga BP, da Costa Junior LB, Lambertucci JR 2003. Magnetic resonance imaging of cerebellar schistosomiasis mansoni. Rev Soc Bras Med Trop 36: 635-636.

Cota GF, Pinto-Silva RA, Antunes CM, Lambertucci JR 2006. Ultrasound and clinical investigation of hepatosplenic schistosomiasis: evaluation of splenomegaly and liver fibrosis four years after mass chemotherapy with oxamniquine. $\mathrm{Am}$ J Trop Med Hyg 74: 103-107.

Coura JR, Amaral RS 2004. Epidemiological and control aspects of schistosomiasis in Brazilian endemic areas. Mem Inst Oswaldo Cruz 99 (Suppl. 1):13-19.

Gerspacher-Lara R, Pinto-Silva RA, Rayes AA, Drummond SC, Lambertucci JR 1997. Ultrasonography of periportal fibrosis in schistosomiasis mansoni in Brazil. Trans $R$ Soc Trop Med Hyg 91: 307-309.

Gerspacher-Lara R, Pinto-Silva RA, Serufo JC, Rayes AA, Drummond SC, Lambertucci JR 1998. Splenic palpation for the evaluation of morbidity due to schistosomiasis mansoni. Mem Inst Oswaldo Cruz 93 (Suppl. 1): 245-248.

Lambertucci JR, Cota GF, Pinto-Silva RA, Serufo JC, Gerspacher-Lara R, Drummond CS, Antunes CM, Nobre V, Rayes A 2001. Hepatosplenic schistosomiasis in field-based studies: a combined clinical and sonographic definition. $\mathrm{Mem}$ Inst Oswaldo Cruz 96 (Suppl. 1): 147-150.

Lambertucci JR, Gerspacher-Lara R, Pinto-Silva RA, Barbosa 
MM, Teixeira R, Barbosa HF, Serufo JC, Rezende DF, Drummond SC, Rayes AA 1996. The Queixadinha Project: morbidity and control of schistosomiasis in an endemic area in the northeast of Minas Gerais, Brazil. Rev Soc Bras Med Trop 29: 127-135.

Lambertucci JR, Rocha RS, Carvalho OS, Katz N 1987. Schistosomiasis mansoni in Minas Gerais. Rev Soc Bras Med Trop 20: 47-52.

Lambertucci JR, Serufo JC, Gerspacher-Lara R, Rayes AA, Teixeira R, Nobre V, Antunes CM 2000. Schistosoma mansoni: assessment of morbidity before and after control. Acta Trop 77: 101-109.

Lambertucci JR, Silva LC, Andrade LM, de Queiroz LC, PintoSilva RA 2004. Magnetic resonance imaging and ultrasound in hepatosplenic schistosomiasis mansoni. Rev Soc Bras Med Trop 37: 333-337.

Lambertucci JR, Sousa-Pereira SR, Silva LC 2005. Myeloradiculopathy in acute schistosomiasis mansoni. Rev Soc Bras Med Trop 38: 277-278.

Petroianu A 2003. Surgical treatment of portal hypertension in schistosomiasis mansoni Rev Soc Bras Med Trop 36: 253265.

Pinto-Silva RA, Abrantes WL, Antunes CM, Lambertucci JR 1994. Sonographic features of portal hypertension in schis- tosomiasis mansoni. Rev Inst Med Trop São Paulo 36: $355-$ 361.

Prata A 2004. The role of the scientific research in the control of schistosomiasis in endemic areas. Mem Inst Oswaldo Cruz 99 (Suppl. 1): 5-11.

Richter J, Domingues AL, Barata CH, Prata AR, Lambertucci JR 2001. Report of the second satellite symposium on ultrasound in schistosomiasis. Mem Inst Oswaldo Cruz 96 (Suppl. 1): 151-156.

Serufo JC, Antunes CM, Pinto-Silva RA, Gerspacher-Lara R, Rayes AA, Drummond SC, Reis CM, Martins MJ, Mingoti SA, Lambertucci JR 1998. Chronic carriers of hepatitis B surface antigen in an endemic area for schistosomiasis mansoni in Brazil. Mem Inst Oswaldo Cruz 93 (Suppl. 1): 249-253.

Silva LC, Kill CM, Lambertucci JR 2002. Cervical spinal cord schistosomiasis. Rev Soc Bras Med Trop 35: 543-544.

Silva LC, Maciel PE, Ribas JG, Pereira SR, Serufo JC, Andrade LM, Antunes CM, Lambertucci JR 2004a. Schistosomal myeloradiculopathy. Rev Soc Bras Med Trop 37: 261-272.

Silva LC, Maciel PE, Ribas JG, Souza-Pereira SR, Antunes CM, Lambertucci JR 2004b. Treatment of schistosomal myeloradiculopathy with praziquantel and corticosteroids and evaluation by magnetic resonance imaging: a longitudinal study. Clin Infect Dis 39: 1618-1624. 